\title{
Parasitoids of leafrollers (Lepidoptera:Tortricidae) from scrub vegetation near horticultural areas in Nelson
}

\author{
P.W. Shaw and D.R. Wallis \\ The New Zealand Institute for Plant \& Food Research Limited, Old Mill Road, \\ RD 3 Motueka 7198, New Zealand \\ Corresponding author:peter.shaw@plantandfood.co.nz
}

\begin{abstract}
Leafroller larvae and pupae were collected during timed searches in January and April 2013 from host plants at six scrub vegetation sites in two Nelson horticultural districts approximately $40 \mathrm{~km}$ apart. The numbers of leafrollers and parasitoid species recovered were similar in both districts. Most of the leafroller larvae collected were Epiphyas postvittana (Walker) (lightbrown apple moth, LBAM), and most of these were found on gorse and broom. In total, 293 larvae and 11 pupae were reared successfully, with 39\% parasitism. A wide diversity of parasitoids was recovered, comprising 10 species from five families, with Dolichogenidea tasmanica (Braconidae) the most common (80\%). The diversity of parasitoids and parasitism of leafrollers in unmanaged environments outside orchards may help to reduce leafroller pressure and the risk of fruit infestation in surrounding commercial orchards.
\end{abstract}

Keywords parasitoids, leafrollers, Tortricidae, parasitism, unmanaged environments.

\section{INTRODUCTION}

Leafrollers (Lepidoptera: Tortricidae) are important quarantine pests in pipfruit orchards and infested fruit can result in rejection of export consignments. The lightbrown apple moth (Epiphyas postvittana, LBAM) is an Australian species found throughout New Zealand and has a wide host range (Dugdale \& Crosby 1995), with 265 host plants (Thomas 1989), including many horticultural crops (Wearing 1994). Lo et al. (2000) found $96 \%$ of leafrollers infesting apple foliage and fruit in Nelson orchards over 3 years were LBAM. It is the most abundant species in Nelson (Suckling et al. 1990) and is commonly found in areas of scrub vegetation, particularly gorse and broom, scattered around the horticultural environment in the Nelson region. Leafroller numbers are generally low in insecticide-treated apple orchards, so unmanaged scrub environments provide a better opportunity in which to assess leafroller parasitism and parasitoid fauna.

These unmanaged scrub vegetation areas provide refuges for leafrollers, which may move into nearby orchards and other horticultural crops, particularly vineyards and boysenberry gardens that occur amongst pipfruit orchards in Nelson. The proximity of orchards to noncrop host plants can influence the leafroller pressure on individual orchards. For leafroller control in the pipfruit industry's Integrated Fruit Production (IFP) programme, growers apply a limited number of well-timed insecticides based on leafroller phenology and in response to exceeding pheromone trap-based thresholds 
during the season. Early season phenology-based insecticide sprays control any resident leafrollers in the orchard, so these spray thresholds are more likely to be exceeded on orchards exposed to high leafroller pressure from host plants outside the orchard. Biological control is also an important component of leafroller management and parasitism of leafrollers in unmanaged vegetation areas may help to reduce leafroller pressure on nearby orchards and other horticultural crops.

As the lightbrown apple moth is abundant in areas of gorse and broom and is the most important orchard pest leafroller in Nelson, the objective of this study was to assess LBAM populations, parasitoid fauna and parasitism in this habitat.

\section{METHODS}

\section{Scrub sites}

Areas of scrub vegetation dominated by gorse Ulex europaeus (L.) and broom Cytisus scoparius (L.) are scattered throughout the Nelson region. Three typical scrub sites in the Motueka and Waimea horticultural districts (approximately $40 \mathrm{~km}$ apart) were chosen to determine if there were any differences in LBAM populations and associated parasitoids in these districts.

\section{Pheromone traps}

LBAM pheromone trap catches were used to reflect leafroller numbers in the scrub habitat during January and April when the leafroller searches were conducted. Two LBAM pheromone traps at each of the monitoring sites in Motueka and Waimea were checked weekly from 30 December 2012 to 28 January 2013, and 25 March to 15 April 2013. The number of LBAM males trapped was recorded and sticky bases $(19 \times 18 \mathrm{~cm})$ were changed weekly. Over the same periods, two LBAM traps were monitored in three apple orchards in each of the two districts to provide a comparison with leafroller numbers in the scrub habitats.

\section{Timed searches and rearing}

Between 17-23 January2013 and 22-24 April 2013, six leafroller searches, each of 3 min duration, were carried out by two people (18 minutes of combined search time) at each site. During visual searches, evidence of larval infestation of foliage was sought and suspected infested foliage including feeding damage, larval webbing and distorted foliage was collected and placed in a labelled plastic bag for later examination with a binocular microscope. Leafroller larvae were removed from the host plant, placed into plastic tubes containing artificial diet (Singh 1983) and reared to fate at approximately $20^{\circ} \mathrm{C}$. Eleven leafroller pupae were found during searches and these were reared under the same conditions to emergence. Almost all the larvae that were reared successfully were LBAM, and unidentified leafrollers that emerged and larvae that died during rearing were not included in the analysis of data presented. Parasitism figures presented in the tables are derived from parasitoids that emerged from successfully reared leafroller larvae (and 11 pupae) and do not include parasitoid pupal cocoons (which may or may not have emerged) found during searches for larvae.

Parasitoids that emerged after rearing were identified from specimens provided from the New Zealand Arthropod Collection (Landcare Research, Auckland, New Zealand).

\section{RESULTS AND DISCUSSION}

Weekly mean pheromone trap catches of male LBAM over the January and late March-April monitoring periods at the Motueka and Waimea scrub sites were 7-16 times higher than those in the apple orchards in each district respectively (Table 1). This would indicate large populations of LBAM occupied the areas of scrub vegetation. Suckling et al. (1998) reported that in a survey of leafrollers on selected host plants, LBAM was the most abundant species identified from gorse and broom in Nelson. Higher numbers of leafroller larvae were collected in January at the Motueka and Waimea sites than in April (Table 1), possibly because the conditions in late summer dried vegetation and restricted new shoot growth on gorse and broom, making them less desirable for infestation by leafrollers.

Parasitism of leafrollers was similar in both districts and increased between January and April (Table 1). There were no obvious differences in the parasitoid species recovered in the two 
Table 1 Mean weekly Epiphyas postvittana (lightbrown apple moth, LBAM) pheromone trap catch of males in three scrub and apple orchard sites in Motueka and Waimea districts, Nelson, along with the numbers of LBAM successfully reared and parasitism (\%) of LBAM collected from scrub sites in January and April .

\begin{tabular}{|c|c|c|c|c|c|}
\hline \multirow[b]{2}{*}{ District } & \multirow[b]{2}{*}{ Date } & \multicolumn{2}{|c|}{ Trap catch } & \multirow{2}{*}{$\begin{array}{l}\text { LBAM } \\
\text { reared }\end{array}$} & \multirow[b]{2}{*}{ Parasitism } \\
\hline & & Scrub & Apple & & \\
\hline \multirow[t]{2}{*}{ Motueka } & January & 82 & 5 & 110 & 40 \\
\hline & April & 93 & 12 & 39 & 48 \\
\hline \multirow[t]{2}{*}{ Waimea } & January & 101 & 11 & 118 & 31 \\
\hline & April & 125 & 17 & 37 & 57 \\
\hline
\end{tabular}

districts. Ten parasitoid species from five families were reared (Table 2). The most abundant species $(\mathrm{n}=96,80 \%)$ was Dolichogenidea tasmanica (Braconidae), followed by Glytopanteles demeter (Braconidae) $(n=9)$. The other eight species identified were individually rare (1-5 specimens). Early records of LBAM parasitism by $D$. tasmanica were reported by Dumbleton (1932, 1935), who showed this species was the most frequent parasitoid found in $20 \%$ to $50 \%$ of larvae reared. Dolichogenidea sp. is the most abundant parasitoid attacking leafrollers on apple foliage (Rogers et al. 2003) and in the absence of disruptive pesticides, Dolichogenidea sp. has been reported to cause 35\% mortality of leafrollers in an apple orchard (Suckling et al. 2001). The present results support those of Suckling et al. (1998) who found D. tasmanica to be the most abundant parasitoid recovered from broom and gorse in Nelson, with $63 \%$ and $32 \%$ parasitism of leafroller larvae on these hosts respectively. In the present study, parasitism of leafrollers on broom, gorse and blackberry, the three main host plants in scrub vegetation found throughout the Nelson region, was 45, 42 and $27 \%$ respectively (Table 2 ).

Table 2 The numbers of Epiphyas postvittana (lightbrown apple moth, LBAM) reared from broom (Cytisus scoparius), gorse (Ulex europaeus), wild blackberry (Rubus fruiticosus) and other host plants; and parasitoid species and parasitism (\%) for host plants and district in Nelson, 2013.

\begin{tabular}{|c|c|c|c|c|c|c|}
\hline \multirow[b]{2}{*}{ Parasitoid species } & \multicolumn{4}{|c|}{ Host plant } & \multicolumn{2}{|c|}{ District } \\
\hline & $\begin{array}{l}\text { Cytisus } \\
\text { scoparius } \\
\text { (broom) }\end{array}$ & $\begin{array}{l}\text { Ulex } \\
\text { europaeus } \\
\text { (gorse) }\end{array}$ & $\begin{array}{l}\text { Rubus fruticosus } \\
\text { (wild blackberry) }\end{array}$ & Other & Motueka & Waimea \\
\hline Dolichogenidea tasmanica (Braconidae) & 59 & 34 & 2 & 1 & 46 & 50 \\
\hline Glytopanteles demeter (Braconidae) & 1 & 6 & 2 & 0 & 7 & 2 \\
\hline Triginospila brevifaces (Tachinidae) & 0 & 4 & 1 & 0 & 3 & 2 \\
\hline Campoplex sp. (Ichneumonidae) & 0 & 3 & 0 & 0 & 2 & 1 \\
\hline Pales funestra (Tachinidae) & 0 & 1 & 1 & 0 & 1 & 1 \\
\hline Meteorus pulchricornis (Braconidae) & 0 & 0 & 0 & 1 & 0 & 1 \\
\hline Goniozus sp. (Bethylidae) & 0 & 0 & 1 & 0 & 1 & 0 \\
\hline Glabidorsum stokesii (Ichneumonidae) & 0 & 1 & 0 & 0 & 0 & 1 \\
\hline Xanthopimpla rhopaloceros (Ichneumonidae) & 1 & 0 & 0 & 0 & 1 & 0 \\
\hline Brachymeria rubripes (Chalcididae) & 0 & 1 & 0 & 0 & 1 & 0 \\
\hline Epiphyas postvittana larvae reared ${ }^{1}$ & 135 & 120 & 26 & 23 & 149 & 155 \\
\hline Parasitism (\%) & 45 & 42 & 27 & 9 & 42 & 37 \\
\hline
\end{tabular}

${ }^{1}$ Includes parasitoids that emerged from larvae. 
The parasitoids identified in the present study were more diverse than those recorded from gorse and broom in Nelson by Suckling et al. (1998). Three species recovered, Glabridorsum stokesii, Xanthopimpla rhopaloceros and Brachymeria rubripes, are pupal parasitoids of leafrollers (Table 2) of Australian origin, which were introduced in 1967-69 and released in Nelson (Thomas 1989). Of particular interest is the present record of a single specimen of B. rubripes, a species which established in Nelson during 1968-73 but has not been reported from field collections since 1975 (Thomas 1989). Triginospila brevifaces, which was released in Nelson in 1999 to assist its natural distribution, was well established by 2000-2001 (Shaw et al. 2001).

Results from this study indicate that areas of the scrub weeds, gorse and broom in particular, harbour large populations of LBAM and provide refugia for a range of leafroller parasitoids. Parasitism (and predation) of leafrollers in areas of scrub may help to reduce leafroller pressure and the risk of leafroller immigration into nearby commercial orchards, where they present a quarantine threat for export fruit. Quantitative studies on the impact of the introduced Australian parasitoids on leafroller populations are needed.

\section{ACKNOWLEDGEMENTS}

We thank Peter Lo and Dave Rogers for their editorial comments on the earlier draft of this paper. This research was funded by the New Zealand Institute for Plant \& Food Research Limited.

\section{REFERENCES}

Dugdale JS, Crosby T 1995. BUGS database of leafrollers and their host plants. Landcare Research, Mt. Albert Research Centre, Auckland, New Zealand.

Dumbleton LJ 1932. The apple leaf-roller (Tortrix postvittana Walker). New Zealand Journal of Science and Technology 14: 83-92.

Dumbleton LJ 1935. Apanteles tasmanica Cam., a braconid parasite of leafroller larvae. New Zealand Journal of Science and Technology 17: 572-576.
Lo PL, Suckling DM, Bradley SJ, Walker JTS, Shaw PW, Burnip GM 2000. Factors affecting feeding site preferences of the lightbrown apple moth, Epiphyas postvittana (Lepidoptera: Tortricidae). New Zealand Journal of Crop and Horticultural Science 28: 235-243.

Rogers DJ, Walker JTS, Moen IC, Weibel F, Lo PL, Cole LM 2003. Understorey influence on leafroller populations in Hawke's Bay organic orchards. New Zealand Plant Protection 56: 168-173.

Shaw PW, Lo PL, Wallis DR 2001. Recent introduction and establishment of the leafroller parasitoid Trigonospila brevifacies (Hardy) (Diptera: Tachinidae) in Nelson. New Zealand Plant Protection 54: 33-36.

Singh P 1983. A general purpose laboratory diet mixture for rearing insects. Insect Science and its Application 4: 357-362.

Suckling DM, Walker JTS, Shaw PW 1990. Reducing insecticide use in pipfruit: Nelson demonstration trials. Proceedings of the $43^{\text {rd }}$ New Zealand Weed and Pest Control Conference: 306-310.

Suckling DM, Burnip GM, Walker JTS, Shaw PW, McLaren GF, Howard CR, Lo PL, White V, Fraser J 1998. Abundance of leafrollers and their parasitoids on selected host plants in New Zealand. New Zealand Journal of Crop and Horticultural Science 26: 193-203.

Suckling DM, Burnip GM, Gibb AR, Daly JM, Armstrong KF 2001. Plant and host effects on the leafroller parasitoid Dolichogenidea tasmanica. Entomologia Experimentalis et Applicata 100: 253-260.

Thomas WP 1989. Epiphyas postvittana (Walker), lightbrown apple moth (Lepidoptera: Tortricidae). In: Cameron PJ, Hill RL, Bain WP, Thomas WP ed. A review of biological control of invertebrate pests and weeds in New Zealand 1874-1987. CAB International, Oxford. Pp. 187-195.

Wearing CH 1994. National leafroller survey: species distribution charts for crops and regions. HortResearch internal report No. IR 94-64, HortResearch, Palmerston North, New Zealand. 